Pp. ii +20 . Washington, D.C.: Government Printing Office, 1959. 20 cents). The lamination process does not degrade cellulose acetate film to a measurable extent. Acid-free papers are not degraded during lamination, but papers containing acid are degraded in proportion to the amount of acid present. Addition of tissue to the laminate increases the tensile strength and internal tear resistance, but decreases edge-tear resistance, compared with that of film alone projecting beyond the paper. Loss of plasticizer with time from a cellulose acetate laminating film does not impair the properties of the laminate. A specification is included for a cellulose acetate laminating film for the purpose, and preliminary results with polyethylene and polyethylene terephthalate are described.

\section{Education and Training in Chemical Engineering}

As a supplement to its booklet, "Chemical Engineering: a Career", the Institution of Chemical Engineers has now issued a supplement entitled "Education and Training in Chemical Engineering", which brings together information published from time to time in its leaflets (pp. 47. Supplement to "Chemical Engineering: a Career". London: Institution of Chemical Engineers, 1959). The information covers scholarships in chemical engineering; lists of university and college scholarships and of industrial organizations with scholarship schemes in chemical engineering; courses in chemical engineering in the United Kingdom; notes on practical training of student apprentices and on graduate training in chemical engineering in the United King. dom; and lists of training schemes for student apprentices, and also for graduates, in chemical engineering in the United Kingdom. Copies are available free of charge on written application to the Institution.

\section{Vivisection}

The Research Defence Society has published a pamphlet giving its views on common misapprehensions about vivisection. This is done by posing a series of questions and providing answers which approximate as closely to the truth as biological research has so far revealed. Among the questions are: What is vivisection?; How is it possible to avoid causing pain to animals?; How does one know that an animal is not suffering pain?; What experiments are performed without anæsthetics?; How many experiments are performed each year on animals?; What sort of results come from experiments on animals and what advances have been brought about by animal experiments? The Society is to be congratulated for the reasoned nature of its reply to the particular question: Why do antivivisectionists oppose animal experiments? The pamphlet can be obtained from the Research Defence Society, 11 Chandos Street, Cavendish Square, London, W.1, price $6 d$.

\section{Effects of Radiation on Human Heredity}

THF first meeting of the World Health Organization. Expert Committee on Radiation was held in Geneva during July 1958. It put forward the suggestion that a study of populations normally exposed to large amounts of background radiation would be useful as a source of information on the genetical effects of radiation on man. At the same time such a study should also provide information on somatic radiation damage. From a survey of known areas of high background radiation, the Kerala area on the soutb-west coast of India was chosen as the only suitable one. Along a hundred miles of coastline in this area the sands contain radioactive monazite, the main source of radioactivity being thorium and its decay products. The population, estimated at 80,000 , receives $10-1$ is times as much background radiation as the average person elsewhere. The Committee laid down general prineiples for the planning of the 'Kerala project'. It recognized that a comparison between the frequencies of specific mutant phenotypes in the irradiated and control populations will scarcely be feasible. Instead, it will be necessary to rely on. comparisons of populations with respect to features like sex-ratio, life-span, fertility, ctc., which are assumed to be influenced by mutations in numerous genes. A plan is drawn up for the levels on which the investigation should be conducted. The general statistical aspects of the problem are considered, and a rough estimate is made of the requirements in. money and personnel.

\section{Home Range in a Feral Goat Herd}

Thane Riney and Graeme Caughley, of the Now Zealand Forest Service, Wellington, New Zealand, have studied the movements of a small population of free-ranging feral goats (Capra hircus) for sixteen months, advantage being taken of individual natural markings adequate for identification of each animal (New Zealand J. Sci., 2, No. 2 ; Jume 1959). In the winter, adult females went into the forest, leaving the nanny-kid herd in the more open area, where study was concentrated. This was an area common to all nanny and kid home ranges, and more than 90 per cent of all observations were made in this herdrange, which was 1,050 yards at its widest diameter. The herd-range consisted of three high-use areas surrounded by areas of less use. In the nanny-kid herd, two groupings were recognized-the family group, and the larger more temporary associations formed within the herd. The herd was never observed all together at any one time. There was no antagonism between groups or associations, and although some aggressive behaviour occurred among billies, no signs of leadership emerged. The boundary of a herd-range appears to be more in the nature of a band or zone than a line, and in this area it is apparently influenced by the availability of cover. Relations between sheep and goats do not appear to affect boundary formation and shooting has not been intensive enough permanently to alter the shape of the herd-range. The nanny-kid herd is considered the part of the population most suitable for the application of management and control measures.

\section{Biology Staining Schedules}

R. R. FoweLL's well-known booklet on the practical details of staining techniques designed for students of intermediate degree standard has been issued in the sixth edition (H. K. Lewis and Co., Ltd. $3 s$. net). Because of the increased importance given to microbiology in medicine, industry and other fields, facilities for training in the subject are now provided by a number of technical colleges and universities. In view of these developments, an additional chapter, entitled "Microbiology Schedules", has been incorporated in the present edition, and the appendix has been extended to include formula for the stains mentioned in these schedules. The staining methods advocated have been limited to those considered most useful for routine purposes. Additional information on dehydration has also been inchuted. 